\title{
ATIVIDADE EMPRESÁRIA E OS DANOS MORAIS PUNITIVOS E AS NOVAS FUNÇÕES DA RESPONSABILIDADE CIVIL NO DIREITO \\ BRASILEIRO
}

\section{BUSINESS ACTIVITY AND THE PUNITIVE DAMAGES AND THE NEW TORTS FUNCTIONS IN BRAZILIAN LAW}

Clayton Reis 1

Gregorio Menzel2

\section{Resumo}

A complexidade das relações humanas e a sociedade de risco contemporânea exigem um reexame do instituto da responsabilidade civil no Direito brasileiro, de forma que tenha efetividade frente as sistemáticas ou maliciosas violações aos direitos fundamentais dos cidadãos e dos grupos afetados. A doutrina e a jurisprudência brasileira, e dos países de tradição civilista, está baseada na ideia de restituição do dano, mas, como demonstram os exemplos dos países que adotam o common law, a responsabilidade civil possui, ainda, funções punitiva e dissuasória. Nesse sentido, a partir da análise do instituto do punitive damages nos EUA e na Inglaterra, será possível compreender $\mathrm{o}$ cabimento $\mathrm{e}$ a constitucionalidade dos danos morais punitivos no ordenamento jurídico brasileiro.

Palavras-chave: Responsabilidade Civil; Danos Morais; Danos Morais Punitivos.

\begin{abstract}
The complexity of human relationships and the contemporary risk society demands a reexam of the Brazilian torts institute, in a way that it has effectiveness regarding the affected citizens

1 Doutor e Mestre em Direito pela Universidade Federal do Paraná. Bacharel em Direito pela Faculdade de Direito de Curitiba. Magistrado em Segundo Grau, aposentado, do TJPR. Professor na Escola da Magistratura do Paraná e pertence ao Corpo Docente Permanente do Programa de Mestrado em Direito Empresarial e Cidadania do UNICURITIBA. Realizou estágio Pós-doutoral na Faculdade de Direito da Universidade de Lisboa-Portugal. Tem experiência em: Direito Civil: Responsabilidade Civil, Dano Moral. Direitos da Personalidade e Cidadania. 2 Mestrando em Direito Empresarial e Cidadania pelo Centro Universitário Curitiba - UNICURITIBA. Pesquisador do grupo de pesquisa Cidadania Empresarial no Século XXI, registrado no CNPq.
\end{abstract}


or groups systematic and malicious fundamental rights violations. Brazilian jurisprudence and precedents, and also civil law tradition countries, are based in damage restitution, but as common law systems demonstrate torts have too punitive and deterrent functions. By the analysis of USA's and England's punitive damages it will be possible to comprehend its constitutionality and fit into Brazilian legal system.

Keywords: Civil Liability; Torts; Punitive Damages. 


\section{INTRODUÇÃO}

A responsabilidade civil é um dos mecanismos mais antigos do direito privado, sendo a forma tradicional para reparação dos danos sofridos pelos indivíduos e pelas empresas frente a um fato jurídico danoso causado por outrem. A tradição do civil law manteve quase que inalterados seus fundamentos e limites desde a sua estruturação no direito romano e canônico, tendo como princípio a restauração do status quo ante, estabilizando as relações jurídicas e limitando-se a reparação até o limite do dano sofrido.

Já o common law, baseado mormente na construção de precedentes e no caso concreto, alterou de forma significativa as funções da responsabilidade civil, gravitando para novas formas de reparação de danos, como os punitive damages, os exemplary damages, e o disgorgement of profits, através da realização de que, para além de restituir os danos causados, a responsabilidade civil somente alcança seus fins de punição e prevenção de atos lesivos quando, em determinados casos, extrapola o quantum devido e se volta ao causador do dano, desincentivando-o de cometer atos contrários à ordem jurídica e afirmando à sociedade que a prática de atos lesivos não será tolerada.

Nesse contexto, o direito civil contemporâneo brasileiro tem se voltado às práticas adotadas, especialmente, nos Estados Unidos da América e na Inglaterra, para as incorporar ao seu sistema constitucional de reparação de dano com o objetivo de coibir as reiteradas práticas danosas que tem inundado o Judiciário e permitido a sistemática desconsideração dos direitos fundamentais de seus cidadãos.

Nesse trabalho, se pretenderá apresentar a visão dogmática tradicional da responsabilidade civil no Brasil, apontar as novas tendências doutrinárias sobre as funções da responsabilidade civil e evidenciar o papel e as possibilidades dos danos morais punitivos no contexto do direito privado brasileiro. 


\section{OS DANOS MORAIS NA DOUTRINA TRADICIONAL}

A doutrina brasileira do direito privado em relação à responsabilidade civil ao pouco se alterou até o advento do Código Civil de 2002, mantendo o mesmo caráter patrimonialista e meramente reconstitutivo do dano. No entanto, o novo contexto neoconstitucionalista do direito privado e a nova compreensão das funções da responsabilidade civil tem alterado significativamente sua feição. Não obstante, é necessário compreender como foi, e, em grande medida, ainda é, tratado o tema pelos autores brasileiros do Direito Civil.

A história da responsabilidade civil tem sua origem na vingança e na proporcionalidade estabelecida na Lei do Talião (olho por olho, dente por dente) que, desde já, previa absoluta identidade entre o agravo e a retribuição (REIS, 2010, pp. 21/23), mas foi no direito romano que foi desenvolvida e sedimentada. Era tida como um sistema contraposto e complementar ao penal, em que os delitos privados passaram a ser arbitrados por juízes na medida do dano cometido, afetando o patrimônio do causador, mas continuando com o caráter público de restituição (FARIAS; BRAGA NETTO, ROSENVALD, 2018, p. 60).

Durante o período do medievo, a responsabilidade toma um caráter puramente privado, sempre buscando a restituição dos danos ocorridos aos direitos individuais e interesses particulares. Passando ao período dos Estados Modernos, as sanções passam a ser arbitradas em nome do interesse público e se separa a pena do dano, abrindo espaço à noção comutativa da responsabilidade, que agrega o valor da restituição e do enriquecimento sem causa, ante a forte influência da doutrina católica no Direito (FARIAS; BRAGA NETTO, ROSENVALD, 2018, pp. 62/64). Desde então, pouco se percebeu de alterações da concepção de responsabilidade civil até o final do século XX, em especial na doutrina do direito privado brasileiro.

A posição clássica da doutrina brasileira foi reproduzida no art. 944 do Código Civil de 2002, que estabelece que "a indenização mede-se pela extensão do dano", tendo como única mitigação expressa a disposição de redução do quantum indenizatório frente excessiva desproporção entre a gravidade da culpa e o dano. Dessa forma, CAVALIERI FILHO (2019, p. 28) que como consequência da interpretação literal do disposto no Parágrafo Único não se é possível existir o dano moral punitivo, pois o legislador apenas autorizou a redução da indenização, alegando que atribuir uma função punitiva para a responsabilidade civil seria subverter a finalidade da norma e do instituto. 
De acordo com o ensinamento de Sérgio Cavalieri Filho, a responsabilidade civil “designa o dever que alguém tem de reparar o prejuízo decorrente da violação de um outro dever jurídico. Em apertada síntese, responsabilidade civil é um dever jurídico sucessivo que surge para recompor o dano decorrente da violação de um dever jurídico originário" (2019, p. 14). Tal definição contém dois signos fundamentais, reparação e recomposição, que indicam que o movimento desejado pela norma jurídica é um movimento reativo e simétrico ao fato causador do dano. O dever de reparação, para o autor, tem um limite negativo, que é a reparação integral, de forma a restaurar o status quo ante, ao mesmo tempo que tem um limite positivo, a proibição ao enriquecimento sem causa, sendo equilibrado pela análise em concreto pelo julgador (CAVALIERI FILHO, 2019, p. 15).

É nesse sentido que Clayton Reis professava, indicando que a restituição integral do dano é o alicerce da responsabilidade civil, devendo existir a perfeita correlação entre o dano sofrido e a indenização, cabendo ao julgador "alterar o quantum indenizatório quando este se revelar como valor exorbitante ou ínfimo, consoante iterativa jurisprudência" (REIS, 2010, p. 199), de forma a se tentar, sempre, alcançar a compensação satisfativa e equivalente da vítima. 


\section{AS NOVAS FUNÇÕES DA RESPONSABILIDADE CIVIL}

Apesar da sedimentada compreensão da reponsabilidade civil como meio tão somente de reparação do dano sofrido pela vítima, os primeiros anos do século XXI apresentam uma significativa e paulatina alteração do instituto, abrindo-o a novas espécies de funções que ampliam a sua capacidade de satisfazer a efetiva proteção dos direitos fundamentais dos cidadãos brasileiros, em compasso com a constitucionalização do Direito Privado.

Um grande exemplo dessa mudança de comportamento da doutrina brasileira sobre a responsabilidade civil é a alteração radical da posição de Clayton Reis sobre o tema. Como já anotado, Reis adotou uma posição contrária à funcionalização da responsabilidade civil para danos exemplares ou punitivos, por exemplo, em suas obras, no entanto, na mais recente edição do seu livro Dano Moral, inverte a sua posição, passando a advogar por essas novas funções e institutos da responsabilidade civil no Direito brasileiro.

\footnotetext{
"Esse contexto de recorrentes violações aos direitos ambientais, consumeristas e de personalidade e, além disso, de grandes empresas e agentes econômicos figurando como litigantes habituais no polo passivo das demandas indenizatórios, levou-nos à reflexão sobre o dogma da tutela reparatória da responsabilidade civil. Após um longo processo de discernimento, apresentamos categoricamente, nesta nova edição do livro posicionamento à contramão do entendimento majoritário sobre as funções da responsabilidade civil” (REIS, 2019, p. 17)
}

Para o autor, a compreensão da responsabilidade civil como tutela dos direitos patrimoniais, com função meramente reparatória, “deu lugar aos conceitos da dignidade da pessoa humana, da solidariedade social, e da justiça distributiva, influenciando profundamente toda a sistemática do dever de ressarcir" (REIS, 2019, p. 158), ou seja, com a constitucionalização do Direito Privado, não se pode mais compreender os institutos presentes no Código Civil de 2002 sem levar em conta os direitos fundamentais na Constituição plasmados.

Ademais, vivemos uma "cultura empresarial da irresponsabilidade", na qual a reiterada prática de lesões é estimulada em razão da certeza de que as, eventuais, indenizações 
a serem pagas serão limitadas à extensão do dano, de sorte que se é economicamente vantajoso agir desconsiderando os direitos dos lesionados.

Dessa forma, o autor propõe "a imposição de uma função da responsabilidade civil para além da meramente reparatória/compensatória" (REIS, 2019, p. 164), que prime pela efetividade mais do que pela neutralidade, ou seja, defende que sejam três as funções da responsabilidade civil: reparatória, preventiva e punitiva. A função reparatória responde à função clássica, focada na vítima e no dano, enquanto a punitiva preconiza a penalização como forma de inibir o causador do dano a reiterar a conduta, e, por fim, a função preventiva mira a inibição de novos danos por outros agentes.

Pretende-se tornar o sistema de reparação civil preventivo, virando uma técnica de controle social, não mais um instituto meramente reativo, reforçando a observância das normas, inibindo de forma eficaz as condutas negativas. Essa sistemática de dissuasão se dá de duas formas, a specific deterrence e a general deterrence, ou dissuasão específica e geral, na qual a primeira atua a desincentivar o agente do ato danoso e a segunda funciona por um condão educativo, desestimulando os potenciais causadores de novos danos a não o fazerem e reforçando a existência de um sistema jurídico que protege os direitos fundamentais dos cidadãos, como ensina Dan B. Dobbs (REIS, 2019, p. 165).

O princípio da solidariedade é um dos fundamentos da nossa sociedade e está absolutamente entranhado em todas as normativas constitucionais brasileiras, e deve ser abordado nos mais diversos institutos jurídicos que percebemos, de forma que a responsabilidade civil não pode se furtar de a levar em consideração. Nesse sentido, o seu foco deve cambiar da contenção de danos para a contenção de condutas (REIS, 2019, p. 166).

Nota-se, também, que esse tipo de função não é inteiramente novo no Direito Privado, pois já está plasmado no Direito Processual Civil brasileiro nas astreintes e na cláusula penal. Assim sendo, ser-se-ia uma ampliação da significação, da efetividade e do alcance das funcionalidades da penalização no Direito Civil, mais que uma inovação completa.

Ainda, a própria norma do art. 944 e seu parágrafo do Código Civil de 2002 não estipula de forma rígida o arbitramento da indenização, pois prevê a possibilidade de mitigação do quantum debeatur ante demasiada desproporção entre o dano e a culpa do agente. É pacífico na doutrina e na jurisprudência a validade do princípio da proporcionalidade nesses casos, remetendo ao juiz estabelecer essa causalidade de forma a racionalizar o instituto. 
Ora, não seria forçoso pensar, por meio da equidade, que em casos em que a culpa do agente é desproporcionalmente superior ao dano causado caiba ao juízo corrigir tal desproporcionalidade na mesma medida em que já se faz nos casos de culpa levíssima. A reiterada, maliciosa e intencional conduta de agentes que violam direitos fundamentais excede gravemente o dano sofrido por determinado indivíduo e atinge frontalmente toda a sociedade, rompendo o tecido dos pactos sociais e do ordenamento jurídico, valendo-se das falhas e das brechas que a racionalidade e a razoabilidade comunitária impediu de normatizar, exigindo, também, uma punição grave.

A principal resistência da doutrina, como observa REIS (2019, pp. 171/173), é a distinção e a confusão entre as searas penal e civil, fundando as suas críticas no princípio da legalidade, ou seja, que não se pode infligir pena a qualquer pessoa sem Lei anterior ao fato. No entanto, apesar da semelhança do signo, as penas civis e penais são absolutamente distintas, de sorte que o formalismo necessário às sanções penais não se aplica ao Direito Privado.

Outro autor que pensa a responsabilidade civil de forma contemporânea é Nelson Rosenvad, que afirma que ela possui quatro funções distintas mas perfeitamente compatíveis entre si: a função de reparar o dano sofrido ao sujeito atingido, a de repristinar o status quo ante, a de reafirmar o poder sancionatório do Estado e a de desestimular novos danos (ROSENVALD, 2017, p. 32). Apesar de as duas primeiras serem pacíficas no civil law, as duas seguintes apenas estão sedimentadas no common law, mas se tornam essenciais para a prevenção de ilícitos e de riscos para perseguir a segurança necessária na sociedade de riscos em que vivemos.

Sustenta que os institutos do Direito, em especial a responsabilidade civil, deve estar em consonância com a realidade social que regula, de forma a apresentar conteúdo e substância para ter efetividade nas relações interpessoais (ROSENVALD, 2017, p. 190). Dessa forma, pela sua própria organização, o common law está na vanguarda da consideração das funções punitiva e precaucional dos damages, mas não há impedimento algum para a sua adoção dos ordenamentos de tradição civilista, dentre eles o Brasil.

Ademais, afirma que a sua institucionalização não seria uma inovação, mas tão somente uma restauração à vocação originária do instituto, que em sua gênese considerava não somente a restauração do dano sofrido, mas a punção "àquele que fere as prescrições impostas em prol do interesse geral" (FARIAS; BRAGA NETTO; ROSENVALD, 2018, p. 
55). Dessa forma, não se é possível conceber a responsabilidade civil sem levar em conta o contexto histórico e social em que está inserida.

\begin{abstract}
A elevação da prevenção ao posto de princípio da responsabilidade civil indica uma quebra de paradigmas mais ampla do que a produzida quando da paulatina ascensão da teoria objetiva da responsabilidade civil, ao longo do século XX. (FARIAS; BRAGA NETTO; ROSENVALD, 2018 , p. 56).
\end{abstract}

E nesse novo contexto, a responsabilidade civil deve tomar um caráter redistributivo, redistribuindo os danos e os riscos que as ações que fogem do concerto jurídico e social que se organiza a sociedade, produzindo coerência ao instituto ante à compreensão de que aqueles não mais se restringem ao lesado, mas à diversos grupos e coletividades e, em última análise, à sociedade como um todo. 


\section{OS PUNITIVES DAMAGES}

Como forma de efetivação das funções punitiva e dissuasória da responsabilidade civil foi criado o instituto dos danos morais punitivos, ou, de acordo com o termo em inglês, punitive damages, que seria melhor representado pela expressão condenação punitiva (ROSENVALD, 2017, p. 191), nos países de tradição costumeira, em especial nos EUA e na Inglaterra.

No país europeu, os punitive damages se restringem a três hipóteses, quais sejam, quando houver disposição legal autorizando: quando for cometido por um funcionário público uma conduta vexatória, opressiva arbitrária ou inconstitucional em face de um cidadão, violando seus direitos fundamentais; e quando o agente que cometeu o dano julgar que a conduta será mais vantajosa que a indenização (ROSENVALD, 2017, p. 193).

Já nos EUA, os critérios para a aplicação dos danos morais punitivos são muito mais largos, exigindo tão apenas - para além da caracterização do dano, por óbvio - o alto grau de reprovabilidade da conduta e o considerável número de vítimas (REIS, 2019, p. 73). A reprovabilidade variará de acordo com a ação que gerou o dano, sendo graduada como acidental, fraudulenta e intencional, de sorte que quanto mais vicioso o ato, mais passível de reprimenda. Enquanto ao número (possível) de vítimas, não precisam elas figurarem no polo ativo da ação, mas é necessário que se identifique que o ato lesivo, ou o conjunto de atos sistemáticos ou reiterados, lesou, lesa ou lesaria um grande número de indivíduos.

Dessa forma, é possível observar que esses dois critérios possuem dupla-função, uma objetiva, sendo necessária a sua constatação para a incidência da pena civil, mas também uma função qualitativa, levando-se em conta os seus diferentes níveis para a arbitração do quantum debeatur.

Uma vez estabelecida a incidência dos punitive damages, cabe ao juiz arbitrar o valor da indenização (ou no caso americano ao júri). Esse norte balizador deve levar em conta quatro aspectos:

$1^{\circ}$ ) grau de reprovação da conduta do agente ofensor; $2^{\circ}$ ) extensão do dano; $3^{\circ}$ ) estimativa de um valor indenizatório capaz de gerar um efeito punitivo na esfera jurídica do ofensor, levando-se em conta a sua situação financeira; e $4^{\circ}$ ) proporcionalidade entre os danos compensatórios (efetivos ou potenciais) e os danos punitivos. (REIS, 2019, pp. 173/174) 
Dessa forma, a formatação do arbitramento dos danos morais punitivos nos EUA segue basicamente o mesmo modelo brasileiro, que estipula que o dano moral deve seguir o tripé da extensão do dano, o tamanho da culpa do agente e a proporcionalidade. Ora, o único novo critério seria a estimativa da capacidade punitiva da indenização, que é sucedâneo lógico do caráter punitivo do punitive damages, que, mesmo assim, está subordinado à situação financeira do ofensor. Não se observa, pois, qualquer impossibilidade da aplicação de tais critérios no Direito Civil brasileiro, muito menos se abre o conceito de forma a possibilitar abusos aos direitos do agente causador pelo Judiciário.

Foi nesse sentido que evoluiu a jurisprudência estadunidense, no sentido de adotar ainda maiores restrições ao arbitramento das indenizações, estipulando uma proporção máxima de dez vezes ao valor do dano sofrido, devendo essa relação ser alcançada por meio da análise da extensão do dano, da diferenciação entre dano físico e moral, da situação de vulnerabilidade da vítima e do dolo do ofensor, estabelecendo a proteção aos direitos fundamentais do causador do dano e evitando possíveis excessos do juiz (ROSENVALD, 2017, pp. 196/197).

Dentro do instituto dos danos morais punitivos nos EUA pode-se fazer a distinção de três formas diferentes em que ocorrem. Os punitive damages tradicionais se voltam a estabelecer uma pena ao agente causador do dano para que não o seja mais vantajoso a violação dos danos da vítima ou do grupo atingido ou para que ele não seja estimulado a cometer novamente aquele dano. Já os exemplar damages tem a função precípua de desestimular a prática do dano por seus pares, de sorte a reforçar as normas de conduta estabelecidas no ordenamento jurídico (ROSENVALD, 2017, p. 194). Por fim, os disgorgement of profits visa restituir ao lesado todos os lucros auferidos pelo agente, que, em tese, superam enormemente o dano sofrido (REIS, 2019, p. 96/97). Imperioso ressaltar que apesar de cada uma dessas formas possuir uma função preponderante, todas as funções estão em ação concomitantemente, razão pela qual todas são tratadas pelo mesmo instituto.

Em resumo, o que se observa é a relevância do dano moral punitivo no contexto de expansão da capacidade de violação sistemática e brutal dos direitos individuais e difusos, de uma lógica empresarial de desconsideração do cidadão, do enorme risco compartilhado em comunidade, e na necessidade de se prevenir ao invés de reparar os danos, de reafirmar as instituições, valores e regras de convivência que permitem a existência comunitária, de inibir e desestimular lógicas e lucros sustentadas na deterioração do interesse coletivo. 
Não seriam, pois, apenas cabível no ordenamento jurídico os punitive damages, seriam mormente instrumentos para a efetivação e proteção dos princípios constitucionais da dignidade da pessoa humana, da cidadania e da solidariedade, exigindo uma conduta ética e respeitosa de todos os cidadãos e grupos em nossa sociedade. 


\section{CONCLUSÃO}

A doutrina e a jurisprudência brasileira estipulam, em homenagem à tradição romana, que a responsabilidade civil possui apenas a função de reparar o dano e de retornar ao status quo ante, de sorte que a indenização se mede na esteira da reparação integral, mas não podendo exceder o quantum do dano em si. É o que prevê o art. 944 do Código Civil de 2002, que apenas permite a mitigação da indenização no caso de absoluto desencontro entre culpa e dano.

Entretanto, diversos autores vêm aventando a possibilidade de a responsabilidade civil possuir novas funções ante a interconexão das relações humanas e da sociedade de risco, pretendendo dar efetividade fática ao instituto, sem manter uma posição estática e meramente reativa. Dessa forma, autores como Nelson Rosenvald e Clayton Reis analisam o punitive damages nos ordenamentos jurídicos inglês e estadunidense e propõe que a responsabilidade civil possua, além da função reparatória, caráter preventivo e punitivo.

Os danos morais punitivos são a ferramenta que efetiva as funções preventiva e punitiva, por meio das formatações dos punitive damages, exemplary damages e disgorgement of profits, e pretendem punir o cometedor do dano nos casos de excessiva culpa ou quando o número potencial de vítimas for muito grande e desestimular o cometimento de novos danos pelo agente ou por seus pares.

Em relação à conformação do instituto ao Direito Privado brasileiro, os autores asseveram que, além do caráter punitivo estar na gênese do instituto, a Código Civil já permite a modulação da indenização em razão da intensidade da culpa, no entanto, somente para minorar o quantum debeatur, devendo ser ampliada a interpretação por equidade.

Para o procedimento de aferimento da indenização, a única alteração seria a necessidade de se estipular capacidade punitiva em relação ao agente causador, o que seria apenas a adequação aos pressupostos do punitive damages, mantendo-se a estrutura de aferimento da extensão do dano, do grau de culpa e da proporcionalidade. Por fim, para além da proporcionalidade, os EUA adicionaram ao princípio um conteúdo material de refreamento, como o limite máximo da indenização de dez vezes ao do dano.

Destarte, foi possível perceber que inobstante a reticência da doutrina e da jurisprudência, a responsabilidade civil está em plena mudança, se atualizando ao contexto social do século XXI, buscando eficiência e efetividade, de sorte que se é possível adotar os punitive damages no Brasil para alcançar esses objetivos - bastando tão apenas uma nova 
interpretação do artigo 944 do Código Civil de 2002 - e se sedimentando a estrutura de prevenção de danos, não mais a de reação. 


\section{REFERÊNCIAS:}

CAVALIERI FILHO, Sergio. Programa de Responsabilidade Civil. 13 ${ }^{\text {a }}$ Edição. São Paulo: Atlas, 2019.

FARIAS, Cristiano Chaves de; BRAGA NETTO, Felipe Peixoto; ROSENVALD, Nelson.

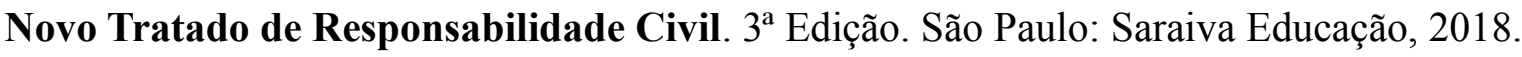

REIS, Clayton. Dano Moral. 5 Edição. Rio de Janeiro: Forense, 2010.

REIS, Clayton. Dano Moral. 6ª Edição. São Paulo: Thomson Reuters Editora, 2019.

REIS, Clayton; KICHILESKI, Gustavo Carvalho. RESPONSABILIDADE CIVIL OBJETIVA DA EMPRESA POR ATOS DE CORRUPÇÃO A LUZ DA LEI 12.846/2013. Revista Juridica, [S.1.], v. 1, n. 46, p. 119-145, jul. 2017. ISSN 2316-753X. Disponível em: <http://revista.unicuritiba.edu.br/index.php/RevJur/article/view/2002/1283>. Acesso em: 18 abr. 2020. doi:http://dx.doi.org/10.21902/revistajur.2316-753X.v1i46.2002.

ROSENVALD, Nelson; MILAGRES, Marcelo. Responsabilidade Civil: novas tendências. $2^{\mathrm{a}}$ Edição. Indaiatuba: Editora Foco, 2018.

ROSENVALD, Nelson. As Funções da Responsabilidade Civil: a reparação e a pena civil. $3^{\mathrm{a}}$ Edição. São Paulo: Saraiva Educação, 2017. 